\title{
ANĀLISES DE LIVROS
}

HANDBOOK OF SENSORY PHYSIOLOGY, VOL. I. PRINCIPLES OF RECEPTOR PHYSIOLOGY. W. R. LOEWENSTEIN, editor. Um volume encadernado $17 \times 25 \mathrm{~cm}$, com 600 páginas e 250 ilustraçōes. Springer Verlag, Berlin-Heidelberg-New York, 1971.

Dentro da Neurofisiologia uma das áreas mais desenvolvidas é a que se dedica ao estudo dos sistemas sensoriais. O acesso eletrofisiológico à maioria dos receptores e a fascinação que as manifestações sensoriais na espécie humana exercem sôbre todos nós, levaram os conhecimentos sôbre essa esfera tão importante da atividade neural a um grau de desenvolvimento realmente extraordinário. Apesar disso não existe tratado algum que, de maneira sistemática, trate adequadamente êsses conhecimntos em todos os sistemas da sensibilidade. Algumas tentativas antigas, como as feitas por Baglioni em sua Vergleichende Physiologie e a do Handbuch der normalen und pathologischen Physiologie, editado por Hans Bethe há mais de quarenta anos, conseguiram ser melhores do que as que se seguiram, inclusive a tímida seção de Neurofisiologia do Handbook of Physiology, editado pela American Physiological Society. Com o início da publicação do Handbook of Sensory Physiology parece, afinal, que nos encontramos diante de obra de fôlego sôbre os sistemas sensoriais. Embora no prefácio Autrum, Jung, Loewenstein, McKay e Teuber, especialistas conhecidos nesse campo, não o considerem um tratado enciclopédico, o primeiro volume prenuncia o contrário. Se os demais volumes da obra forem da mesma categoria do primeiro, o livro será um marco na literatura neurofisiológica. Estão programados oito volumes para o Handbook; o sétimo, porém, dedicado à visão (sem dúvida o mais bem estudado dos sistemas sensoriais) é constituido de quatro volumes, elevando - número real a onze. O primeiro contém 600 páginas, o que faz prever um total de mais de 6.000 páginas, uma vez que o assunto de cada um dos volumes programados preencherá fácilmente outras 600 páginas cada um.

Tècnicamente o volume já publicado é da mais alta qualidade. Um "erratum" anexado ao volume e a mistura de tipos de papel utilizado não diminuem de modo algum sua qualidade, tāo característica da Springer verlag. Quanto ao conteúdo o nivel pode ser considerado elevadíssimo. Um dos aspectos básícos da fisiologia das sensações é a transdução nos receptores, isto é, a transformação dos diferentes tipos de energia (a que as terminações são sensiveis) em sinais elétricos. A transduçāo é um processo essencial porque permite transformar em diferenças de potencial de amplitude (no receptor) e de frequiência (na fibra aferente) variáveis as caracteristicas quantitativas dos estímulos. Sua natureza é ainda um enigma mas já se esboçam esquemas eficazes de abordagem do problema, como se vê nos capítulos escritos por Katchalsky e Oplatka e por Teorell e Flock. Eletrofisiològlcamente o problema é amplamente tratado por Loewenstein, por Fuortes e outros.

Bastante deslocado no contêxto geral encontra-se o capitulo 2, escrito por Nachmansohn, a respeito de "receptores" à acetilcolina na membrana do neurônio. O emprêgo do têrmo "receptores" para denominar os radicais da membrana que reagem com os mediadores e drogas farmacològicamente ativas é desaconselhável pela confusāo que cria em relacāo aos receptores sensoriais, o que no livro ora analisado é particularmente acentuada. O térmo "aceptores", que atualmente adotamos para os radicais da membrana, evita a confusão porque permite distinguí-los das terminaçōes sensoriais. Se um capitulo do livro devesse ser dedicado ao estudo genérico das membranas, o que seria excelente, teria que preceder todos os demais. De qualquer forma, a abordagem de Nachmansohn não é a mais indicada para a 
natureza do livro e pouco tem em comum com o restante, além da confusão dos térmos "receptores" e "aceptores".

Clara exposição do problema da relação quantitativa entre estimulo e sensacão constitui o capitulo 7 , escrito por Stevens, redescobridor da lel de potência para exprimir essa relação. Durante mals de trinta anos Stevens vem trabalhando e lutando para substituir a lei psicofisica logaritmica de Fechner pela de poténcia; no presente volume expóe mais uma vez os argumentos de natureza experimental que apoiam a lei de potência contra a logarítmica. $O$ capítulo 7 resume bảsicamente o que o autor já publicou em revistas especializadas e, a nosso ver, encerra a etapa do estabelecimento da lei genérica que rege a relação estímulo/intensidade de sensação.

O capitulo 12, eserito por Cone e Pak, é talvez a primeira revisão completa a respeito do potencial receptor precoce causado na retina pelos estímulos luminosos, como primeira manifestação do processo de transdução foto-eletrica dos cones visuais. São excelentes os capitulos escritos por Ottoson e Shepherd e por Flock, respectivamente, sóbre a ativação dos receptores dos fusos neuromusculares e das células ciliadas (que são os elementos receptores do aparélho auditivo, do vestibular e da linha lateral dos peixes).

Em suma, pode-se afirmar que o primeiro volume do Handbook of Sensory Physiology é leitura de inestimável valor para os neurofisiologistas, sobretudo os que se dedicam ao estudo dos sistemas sensoriais. Para os neurologistas, embora muitos capitulos constituam tratamento especializadissimo dos aspecto biofísicos do funcionamento do receptores, o livro pode ser de grande utilidade. Por certo os volumes vindouros seräo de maior interésse para os clínicos que o primeiro, que trata apenas dos fenômenos básicos da sensibilidade.

Cesar timo-Iaria

EXTRACRANIAL OCCLUSIVE CEREBRO-VASCULAR DISEASES. DIAGNOSIS AND MANAGEMENT. EDWIN J. WYLIS e WiLliaM K. EHRENFELd. Um volume encardenado com 231 páginas. W. B. Saundres Co., Philadelphia-London-Toronto, 1970.

Vem sendo realçada cada vez mais a importáncia dos vasos extracranianos que contribuem para a circulação sangüinea do encéfalo, sendo admitido que cêrca de 30 a $40 \%$ dos pacientes com insuficléncia cérebro-vascular apresentam uma afeccão oclusiva extracraniana bastante significativa. Como os processos obstrutivos arteriais em nível torácico ou cervical são freqüentemente accessiveis à cirurgia, tornando o prognóstico muito mais favorável, compreende-se a importåncla do estudo da patologia vascular extracraniana. Neste livro os autores, especializados em cirurgia vascular e docentes na Universidade da Califórnia, avaliam os efeitos da cirurgia reconstrutiva arterial no tratamento da insuficiêncla cérebro-vascular. Nos primeiros capitulos são rememorados os dados relativos à anatomia da circulaça cerebral e à fisiopatologia da afeccāo cérebro-vascular oclusiva, sendo avaliadas as diferentes sindromes neurológicas determinadas pelas oclusões parciais ou totais de vasos extracranianos. No 5.0 capitulo, em colaboraçāo com William B. Hoyt, é estudada a participação oftalmológica que, com frequêencla, denuncla a séde do processo oclusivo. A semiologia vascular e os exames arteriográficos da circulação cerebral são esmiuçados no 6.0 capitulo e, no seguinte, são avaliadas as indicaçōes e contraindicações das intervençōes cirúrgicas. Em capitulo especial são estudados, com a co-autoria de C. Philip Larson Juntor, os tipos de anestesia mais adequados, assim como os cuidados para o contrôle da circulaçāo cerebral durante as intervenções círúrgicas cujas técnicas e complicações são abordadas na parte final. A reuniâo de dados rlínicos e paraclínicos foi facilitada pelo emprégo de um protocolo prospectivo preparado em colaboracāo com neurologistas, neurocirurglóes e especlalistas em cirurgia vascular. Nesse trabalho poi acumulada a experiêneia haurida em uma sérle de mais de 1000 pacientes com presumivel insuficiência côrebro-vascular, admi- 
tidos no Medical Center da Universidade da Califórnia durante 12 anos; neste grupo foram feitas 831 intervençóes reconstrutivas arteriais e todos os pacientes foram acompanhados por um periodo minimo de 6 meses, com uma média de seguimento de mais de 4 anos. Os autores dão grande Importâncla à semiologia vascular. A reduçāo da intensidade da pulsacão da artéria carótida comum seria o único dado sugestivo de decréscimo da circulação cerebral. Como processo semiológico mais adequado, é recomendado o deslocamento da artéria carótída lateralmente e sua compressão contra a superficie das vértebras cervicais. Entretanto, os autores salientam que uma artéria trombosada poderá parecer pulsátil por efeito da transmissão do fluxo aórtico forçado contra a porção cervical da artéria carótida. O diagnóstico será reforçado pela ausculta de um ruído sistólico. o ruído causado pela estenose ao nivel da bifurcação pode variar de intensidade e timbre, dependendo do grau da obstruçāo. Na avaliação final os autores analisam separadamente os resultados de intervençôes ao nivel da bifurcação carotidea (738 intervenções em 584 pacientes) daquelas realizadas sỏbre os ramos do arco aórtico e sôbre as artérias vertebrais (92 casos).

R. melaragno filho

DIE FRONTOBASALE SCHADELHIRNVERLETZUNG. HERMANN DIETz. Monografia (16,5 x 24) com 165 páginas, 31 llustrações e 21 tabelas. Volume n.o 130 da série Monographien aus dem Gesamtgebiete der Neurologie und Psychiatrie. Springer Verlag, Berlin-Heidelberg-New York, 1970.

Entre os traumatismos cranianos devidos a acidentes automobilisticos destacam-se os frontobasais não só pela alta frequiência como por constituirem um grupo especial no qual a ocorrência de fratura do endocrânio no teto nasal e nos seios paranasais e concomitante dilaceração da dura-mater basal determina ampla comunicação entre a cavidade craniana c o meio externo, fazendo com que êsses traumatismos, potencialmente abertos, sejam motivo de graves e múltiplas complicaçōes. As particularidades e a posição nosológica destas Iesōes em traumatologia craniana são fornecidas pela sintomatología mais ou menos uniforme, pela freqüência e variedade das complicaçōes e pela exigência de tratamento cirúrgico direto e imediato. Não há duvidas quanto à necessidade das intervençōes cirúrgicas, sendo apenas discutido ainda o típo e a extensāo do ato cirúrgico imediato e é êste o assunto que motiva esta monografia de Hermann Dietz, apresentada como tese de docência. Depois de introduçāo na qual estuda particularidades e as linhas de força neste tipo de traumatismo, o autor refere os aspectos clinicos e as complicações das lesōes contundentes frontobasais, destacando a liquorréia e os distúrbios olfativos, visuais e hipófísotalámicos. No capitulo referente ao tratamento cirúrgico, baseado em extensa revisão bibliográfica e vultosa casuística pessoal, o autor procura delinear as normas gerais para a conduta do cirurgião, expondo os métodos rinológicos e os neurocirúrgicos, optando pela escolha dêstes últimos, mediante abordagem direta transfrontal da fossa cranlana anterior. Só assim será possivel a reconstrução da dura-mater e o fechamento efetivo e eficaz das soluções de continuidade da porção anterior da base do crânio determinadas pela violência do traumatismo, sendo eliminadas as ruinosas complicaçōes.

JUVENAL ROGÉRIO

THE EDUCATION OF A NEUROSURGEON. REPORT OF THE SECOND WORKSHOP FOR NEUROSURGICAL TRAINING PROGRAM DIRECTORS. Suplemento do Journal of Neurosurgery vol. 34, número 2 (fevereiro), 1971.

Tendo em vista a identificação e definição dos alvos do treinamento em neurocirurgia, foi constituído um Comité encarregado da organização de programas de treinamento neurocirúrgico. Este comitê, presidido por Henry Schwartz (St. Louis), tem o patrocinio da Soclety of Neurological Surgeons e do National Institut of Neurological Diseases and Stroke (Washington, D.C.). Constituido o grupo de tra- 
balho, cada um de seus elementos recebe um assunto que é distribuido por várias equipes e, depois, discutido em sessão plenária do grupo. Os relatórios são então levados ao Comitẽ que se encarrega de analizá-los e, com base nesses relatóríos, estabelecer as resoluções. Esta é a publicacão dos relatórios do segundo grupo de trabalho, integrado por Theodore Kurge, Thomas C. King, Robert F. Mager, Donald F. Pochycy, Joseph Ransohoff e Anthony J. Raimondi.

O conclave foi aberto por uma introdução (A. J. Raimondi), seguida das palavras de acolhimento por parte do Presidente do Comitẽ e duas palestras versando sôbre "Metamorfose em educação neurocirúrgica" (T. Kurge) e "Progressos na ciência de educação de adultos" (T. C. King). Os trabalhos fundamentais foram: "Comentários sôbre os alvos da educação neurocirúrgica" (R. F. Mager), "Técnicas de ensino" (J. Ransohoff, M. V. Benjamin e E. R. Tichaner) e "O Residente e a Neurocirurgia" (A. J. Raimondi). Da discussão dêsses trabalhos ficou assentado que o neurocirurgião deve ser adestrado em diferentes campos, assim divididos: a) não clínicos (neuranatomia, neurofisiologia, neuroquímica e neurofarmacologia); b) paraclínicos (mictobiologia, micropatologia, EEG, EMG e cintilografia cerebral); c) neurocirurgia clínica, incluindo cirurgia geral, anestesiologia, ortopedia, neuro-oftalmologia, neuro-patologia, clínica neurológica, neurorradiologia, radiologia terapêutica e conhecimentos dos aspectos nāo técnicos da neurocirurgia, como desenvolvimento histórico, estrategias, convençōes e princípios gerais, além do adestramento nas técnicas neurocirúrgicas. Para cada um dos itens foi elaborada lista dos conhecimentos minimos exigidos.

Das resoluções, expressão da letra e espirito desta reunião para estudo de um programa de treinamento de neurocirurgiões, mencionaremos algumas que nos pareceram dignas de ênfase: a) é recomendável um ano de cirurgia geral em atividades consideradas apropriadas para a neurocirurgia; b) embora todos os residentes devam ser preparados em todos os setores da neurocirurgia, a pediátrica e a estereotáxica demandam especializaçōes; c) cirurgias delicadas como, por exemplo, a dos aneurismas intracranianos deveriam ser centralizadas em serviços especializados; d) no tocante á neurorradiologia, conquanto ramo da radiologia geral, cabe ao neurocirurgião, a escolha do tipo de exame em cada caso, situação que deverá mudar com a evoluçāo no sentido de se constituir a neurorradiologia em especialidade dentro da Neurologia.

\section{J. ZACLIS}

PUlsatile ECHO-ENCEPHAlogRaphy. J. K. Campbell, J. M. ClaRk, D. N. White e C. O. Jenkins. Monografia (16 x 24) com 57 páginas e 40 ilustrações. Suplemento n.o 45 da Acta Neurologica Scandinavica, E. Munksgaard, Copenhagen, 1970.

Esta monografia expōe uma série de pesquisas feitas com aparelho de ultrasson especialmente construido com a finalidade de elucidar os mecanismos responsáveis por dois fenómenos anteriormente descritos: pulsações em amplitude das reflexōes ináividuais das ondas ultrassônicas e modulações da linha de base do traçado ecoencefalográfico (pulsaçōes do alinhamento). As pulsaçōes das ondas ecoencefalográficas, tanto em amplitude como no alinhamento, têm freqüentemente forma e tempos de retardo e de incremento idênticos; no entanto, isto nāo ocorre de maneira invariável. Os estudos sugeriram que a amplitude de um eco é determinada não apenas pela quantidade de energia recebida e refletida por uma interface cerebral, mas também é influnciada pela inclinação e pelo comportamento das interfaces mais superficiais. O principal achado dêste trabalho é que a maioria das interfaces cerebrais sāo desviadas em direção à linha média durante a sístole cardíaca. As modificaçōes pulsáteis dos ecos, que parecem ser originadas nas paredes do terceiro ventrículo, indicam que esta cavidade é comprimida de ambos os lados com a chegada da onda de pulso arterial aos tecidos cerebrais adjacentes. Registros feitos com osciloscópios calibrados mostram que tais movimentos variam de 0,01 a $0,2 \mathrm{~mm}$. 
Foi estudada a influência sôbre a pulsaçāo dos ecos dos seguintes fatôres: apnéia, hiperventilação, compressão das veias jugulares e manobra de Valsalva. Os resultados obtidos indicam que o ultrassom pode detectar o pulso da onda arterial e alguns de seus efeitos sôbre o cérebro. As pulsaçōes do alinhamento podem ser consideradás como indicativas de movimentos de uma interface produzidos por expansão do tecido cerebral adjacente. A intensidade do movimento depende do grau de expansão produzido pela passagem da onda arterial. Os deslocamentos centrípetos da maioria das interfaces estudadas sugerem que a compressão dos ventriculos está envolvida na circulação do liquido cefalorraqueano. As modificaçôes de pulsação dos ecos durante a apéia e hiperventilação indicam, provàvelmente, que a têcnica empregada é bastante sensivel para detectar vasodilatação e vasoconstrição cerebrais. Como conclusāo final destas pesquisas os autores sugerem que a ecoencefalografia pulsátil pode ser desenvolvida no sentido de se constituir em método útil para a investigação da circulação cerebral.

Walter C. PEREIRA

REEDUCATION MOTRICE DES AFFECTIONS NEUROLOGIQUES. J. P. HeLD e E. PIerrot-Deseilligny. Um volume $(16 \times 24,5)$ com 200 páginas e 41 ilustrações. J. B. Baillière et Fils, Paris, 1969.

Este livro é a primeira obra na França versando sóbre reeducaçāo aplicada à Neurologia. Trata-se de compêndio que, de forma clara e concisa, apresenta os principais problemas relativos à reeducação dos pacientes neurológicos. O livro permite, na primeira parte, avaliar, mediante diversos testes, o estado do paciente e as possibilidades da reeducaçāo; na segunda, trata dos princípios gerais da reeducação, sendo as partes finais dedicadas aos métodos de reeducacão motora nas moléstias do sistema nervoso periférico, dos músculos e do sistema nervoso central. $\mathrm{Na}$ parte referente à avaliação dos déficits motores os autores dão ênfase aos testes musculares, chamando a atenção para as principais dificuldades, segmento por segmento, e o modo mais simples de contorná-las. Para a avaliação da função do sistema nervoso central, são apresentados modêlos de fichas de testes de avaliação de hipertonia e de fôrça muscular. Os principios gerais da reeducação são comentados quanto ao tratamento preventivo e às técnicas curativas analíticas e globais, bem como quanto ao tratamento específico de hipertonias. $\mathrm{Na}$ análise da técnica de Kabat é demonstrado que todo trabalho para refôrço da musculatura aumenta a hipertonia e as sincinesias, sobretudo se a hipertonia fôr de caráter espástico. Por isso os autores preferem as técnicas analiticas nos casos de pacientes com afecçôes centrais deixando as técnicas globais para os casos de acometimento periférico. A reeducação das doenças do sistema nervoso periférico e de músculos é apresentada de maneira esquemática, sendo em todos os casos fornecidos elementos para o prognóstỉco. Nos capitulos concernentes à reeducaçāo motora dos pacientes com lesões do sistema nervoso central é feita distinção entre os casos de paraplegias evolutivas e nāo evolutivas; nestas será possivel pensar, desde o primeiro instante, em obter real reabilitaçāo em todos os seus aspectos, enquanto que naquelas a reeducaçāo tem pretensões mais modestas, servindo às vêzes apenas como apôio psicológico. Contudo os autores acentuam que a atitude a tomar nestes casos deve, em princípio, ser a mesma que nos casos evolutivos. As hemiplegias são avaliadas e analisadas com minúncias. Para a recuperação funcional dos hemiplégicos são aproveitadas as sincinesias e as mudanças de posição para promover a facilitação neuromuscular. A reeducação das síndromes parkinsonianas mereceu capitulo à parte dada a importância, para êstes pacientes, da manutençāo de atividade física, pelo maior tempo possível. Terminando o livro os autores tecem comentários sôbre as possibilidades da reeducaçāo nas enfermidades motoras cerebrais relembrando um ensinamento de Tardieu: para a eficácia da reeducação é necessário que o nivel intelectual do paciente seja normal ou pelo menos subnormal. 
ELECTRODIAGNOSTICO $\mathrm{Y}$ ELECTROMIOGRAFIA. SIDNEY LICHT, editor. Um volume encadernado com 496 páginas, 173 figuras e 9 tabelas. Versão castelhana. Editorial Jims, Barcelona, 1970.

Este livro que, na versão original inglêsa, é considerado como essencial em relacāo ao assunto versado, e posto ao alcance do público íbero-americano, com esta edição em castelhano. Sua finalidade é de comunicar a experiência pessoal de vários autores na aplicação de técnicas de neurofisiologia ao diagnóstico e prognóstico de doenças do sistema nervoso periférico e do sistema muscular. Os 17 capítulos foram escritos por 18 autores, dominadores da sua especialidade e alguns dêles iniciadores das técnicas que divulgam. Os mais interessantes, pela sua novidade em nosso meio, são os dedicados á biopsia da placa mio-neural e às curvas de intensidade-duração. Como os capitulos dedicados às técnicas de estimulação de nervos periféricos, os dois capitulos dedicatos à eletromiografia sāo claros, ilustrados com numerosas figuras. A interpretação dos electromiogramas, baseada no estudo do repouso muscular e da contração máxima, é analisada detalhadamente, permitindo ao leitor avaliar a importância dêstes métodos e a utilidade de sua combinação para o diagnóstico diferenclal e prognóstico de moléstias neuro-musculares. Os três últimos capitulos são dedicados à resistência elêtrica da pele, á eletrencefalografia e à retinografia.

Nenhum capitulo deixa de ter valor informativo e interêsse para o leitor, especialmente para aqueles que lidam com êste tipo de técnicas, e para o clínico interessado em doencas musculares ou em apurar seus conhecimentos em eletrofisiologia e métodos de complementação do diagnóstico clínico.

\section{J. L. ALONSO-NIETO}

\section{LIVROS E MONOGRAFIAS RECEBIDOS}

Nota da Redação - A notificaç̃o dos livros e monografias recebidos não implica em compromisso da revista quanto à publicação de uma apreciação. Todos os livros recebidos são arquivados na biblioieca da Clínica Neurológica da Faculdade de Medicina da Universidade de São Paulo.

PUlsatile EChO-ENCEPHAlogRAPHy. J. K. CAMPbell, J. M. ClaRK, D. N. White e C. O. Jenkins. Monografia (16 x 24) com 57 páginas e 40 ilustrações. Suplemento n.o 45 de Acta Neurologica Scandinavica, E. Munksgaard, Copenhague, 1970.

MORBUS MENIERE. A COMPLEXITY OF PATHOLOGICAL MANIFESTATIONS. EiNAR A. LðCHEN. Monografia (16 x 24) com 31 páginas e 16 tabelas. E. Munksgaard, Copenhague, 1970.

MANUEI, ELEMENTAIRE DE NEUROPATHOLOGIE. R. Escourolle e J. PoIrigr. Um volume $(18,5 \times 25)$ com 204 páginas e 225 ilustraçōes, sendo 6 em côres. Masson et Cie., Paris, 1971. Preço: $49 \mathrm{fr}$.

INFORMATIONSTHEORIE UND PSYCHOPATHOLOGIE DES GEDACHTNISSES. METHODISCHE BEITRÄGE ZUR EXPERIMENTELLEN UND KLINISCHEN BEURTEILUNG MNESTISCHER LEISTUNGEN. A. E. ADAMS. Monografia (16,5 x 24) com 124 páginas e 12 ilustraçōes. Da série Monographien aus dem Gesamtgebiete der Psychlatrie. Springer Verlag, Berlin-Heidelberg-New York, 1971 . Preço: DM 48.

DIE FRONTOBASALE SCHADELHIRNVERLETZUNG. HermanN Dietz. Monografia (16,5 x 24) com 165 páginas, 31 llustraçōes e 21 tabelas. Volume n.॰ 130 da série Monographien aus dem Gesamtgebiete der Neurologle und Psychiatrie. Springer Verlag, Berlin-Heidelberg-New York, 1970. 
EXTRACRANIAL OCCLUSIVE CEREBRO-VASCULAR DISEASES. DIAGNOSIS AND MANAGEMENT. E. J. WYLIS e W. K. EHRENFeld. Um volume com 231 páginas. W. B. Saunders Co., Philadelphia-London-Toronto, 1970.

COMO ENSENAR A PENSAR. Louis E. Raths, Selma Wasserman e outros. Um volume $(13 \times 20)$ com 470 páginas. Da série "Biblioteca del Educador Contemporaneo", volume 19. Versão castelhana do original norte-americano. EditoriaI Paídós, Buenos Aires, 1971.

CULPA Y DEPRESSION. ESTUDIO PSICOANALITICO. LEON GRIMBERg. Um volume (13,5 x 23) com 281 páginas. Volume 19 da série "Biblloteca de Psicologia Profunda”. Segunda edição. Editorial Paídós, Buenos Aires, 1971.

EPISTEMologia Y PSICOlogia dE LA IDENTIDAD. Jean Piaget, Hermine SinClair e VINH BANG. Um volume (15 x 23) com 185 páginas. Volume 26 da série "Biblioteca Psicologias del Siglo XX". Versão castelhana do original francês. Editorial Paidós, Buenos Aires, 1971.

LAS CRANEOESTENOSIS. RAUL MATERA. Um volume (15,5 x 23) com 117 páginas e 26 ilustraçoes. Lopez Libreros Editores, Buenos Aires, 1971.

LES INCAPABLES MAJEURS. G. Nicolas e C. BARReteau. Um volume (15,5 x 24) com 123 páginas. Volume n.o 32 da série "Collection de Medecine Legale et de Toxicologie Médicale". Masson et Cie., Paris, 1971. Preço: 34 F.

PRINCIPLES OF RECEPTOR PHYSIOLOGY. W. R. LOEWENSTEIN, editor. Um volume encadernado $(16,5 \times 25,5)$ com 600 páginas e 310 figuras. Volume 1 da coleçăo "Handbook of Sensory Physiology". Springer Verlag, Berlin-Heldelberg-New York. 1971. Preço: US\$ 46,20.

ELEMENTS DE NEUROLOGIE. F. Contamin e O. Sabourand. Um volume (18 $\times$ 24) com 1407 páginas e 358 figuras. Editions Médicales Flamarion, Paris, 1970.

DIE KONZENTRATIONSLAGERHAFT UND IHRE FOLGEN. P. MATUSSEK et al. Um volume encadernado $(17 \times 23)$ com 272 páginas, 19 ilustraçōes e 73 tabelas. Volume 2 da série Monographien aus dem Gesamtgebiete der Psychiatrie. Springer Verlag, Berlin-Heidelberg-New York, 1s71. Preco: DM 38.

LA DISLEXIA EN LA NINEZ. Julio B. DE QUiRos e M. Della CElla. Um volume (13 x 20) com 373 páginas e 67 ilustraçỏes. Volume 22 da série Biblioteca del Educador Contemporaneo. Segunda edição aumentada. Editorial Paidós, Buenos Aires, 1971.

TRATADO DE MUSICOTERAPIA. E. THAYER GASTON et al. Um volume (16 x 23) com 490 páginas. Versão castelhana do original norte-americano. Editorial Paidós, Buenos Aires, 1971.

L $\Lambda$ PSicologia EVOlutiva DE JEAN PIAGET. JohN H. Flavell. Um volume encadernado $(16 \times 23)$ com 484 páginas. Versão castelhana do original norteamericano. Volume 21 da série Biblioteca Psicologias del Siglo XX. Editorial Paidós, Buenos Aires, 1971.

PSIQUIATRIA DINAMICA. FRANZ ALEXANDER et al. Um volume (21 x 23) com 474 páginas. Versāo castelhana do original norte-americano. Terceira edição. Volume 1 da série Biblioteca de Psiquiatria, Psicopatologia y Psicosomatica. Editorial Paidós, Buenos Aires, 1951.

CEREBRAL BLOOD FLOW. INGER WINSo e EgIL HAGgendal. Monografia $(\mathbf{1 6} \times \mathbf{2 3 , 5 )}$ com 72 páginas, 7 tabelas e 15 figuras. Elanders Boktryckeri Aktiebolag, Göteborg, 1971. 
474 ARQ. NEURO-PSIQUIAT. (SÄO PAULO) VOL. 29, N.० 4, DEZEMBRO, 1971

STUDIES ON PROTEIN METABOLISM IN NEURONAL AND GLIAL CELL-ENRICHED FRACTIONS FROM BRAIN TISSUE. CHRISTIAN BLOMSTRAND. Monografia (17,5 x 25) com 31 páginas. Elanders Boktryckeri Aktiebolag, Göteborg, 1971.

CENTRAL AND PERIPHERAL MECHANISMS INVOLVED IN THE EFFECT OF L-DOPA AND ITS ANALOGUES ON BLOOD PRESSURE. AllaN RUBENSSON. $(18 \times 25,5)$ com 30 páginas. Elanders Boktryckeri Aktiebolag, Göteborg, 1971.

DEPRESSIVE SYNDROME IM KINDES UND JUGENDALTER. G. NisSEN. Monografia $(16 \times 25)$ encadernada com 174 páginas, 51 tabelas e 11 figuras. Volume 4 da série Monographien aus dem Gesamtgebiete der Psychiatrie. Springer Verlag, Berlin-Heidelberg-New York, 1971. Preço: DM 58.

KINDER UND JUGEND PSYChIATRIE. H. HaRbauer, R. LempP, G. Nissen e P. STRUNK. Um volume $(20 \times 27,5)$ encadernado com 392 páginas e 55 ilustrações. Springer Verlag, Berlin-Heidelberg-New York, 1971. Preço: DM 98. 